\title{
Boompa Biomotor Skills Triangle Training Through Biomechanics
}

\author{
Erick Garcia Lasluisa* \\ Universidad de las Fuerzas Armadas ESPE, Ecuador \\ *Corresponding author: Erick Garcia Lasluisa, Universidad de las Fuerzas Armadas ESPE, Ecuador
}

\begin{tabular}{|c|c|}
\hline ARTICLE INFO & ABSTRACT \\
\hline Received: 幽 September 16, 2020 & Citation: Erick Garcia Lasluisa. Boompa Biomotor Skills Triangle Training Through \\
\hline Published: 慧 October 06, 2020 & Biomechanics. Biomed J Sci \& Tech Res 31(1)-2020. BJSTR. MS.ID.005035. \\
\hline
\end{tabular}

\section{Opinion}

According to those established by Bompa, the combination between the biomotor capacities of strength, speed and endurance are essential to achieve sporting success, he also says that at least two dominant capacities are required to reach the peaks of high performance.Following what is established by Bompa and applying the principles of biomechanics to his postulate, from my point of view, the application of biomechanics would be in the learning processes of the technique to establish the reference measurements within the movement patterns and in planning of sports training where its objective is to approach the ideal mathematical models to achieve results in official competitions. That is, to investigate the trend of the marks obtained during official competitions such as the Pan-American games, world championships and Olympic games where the marks obtained will serve to establish the parameters of strength, speed, and resistance necessary to achieve power,

The partial competition model is obtained from the diagnosis of the previous competences that result from the theoretical understanding of the sports performance indicators. FUCHS/ LETZELTER developed a mathematical model of the average development of running speed in men's athletics in the 200-meter test; this method allows diagnosing the sprint. With these theoretical indicators, the conditions and prospects for performance are known in advance, thus establishing the objective values that the components of the mathematical model that predict the result (brand) must achieve.

However, you have to choose the mathematical model that best suits the sport specialty; theoretically, the sports of times and marks are those that can best be predicted because the dynamics of the capacity of acceleration, speed, and resistance force. For example, the running dynamics is a function of the athlete's geometry, therefore considering the values obtained in the mark established by Bolt we have that the reaction speed is 0.142 seconds and as terminal speed we have 12.2 meters per second, which It is also physically possible according to the data obtained in the average speed, the second half of the sprint recorded the value is 12.5 meters per second; which surprisingly equates to $99 \%$ of Bolt's speed. (Urbano, 0. Mathematics, 100 meters flat and Usain Bolt). Taking as a reference the speed with which the cycle of the technique is repeated, we can conclude that it is not the determining factor since the increase in muscle mass and the physiological parameters are those that establish the limit of the possibilities of the athletes (Leoni, MG Sport and change. The appearance of Usain Bolt and the recent paradigm shift in the discipline of one hundred meters flat. Technique and culture from the PostHegelian Philosophical-Social Theory., 257).Now How do we use the data for training planning? And How to use biomechanics to gain thousandths of a second? Well, I will focus on the sports where it moves from point A to point B in the shortest possible time where it is taken as a reference to train, What is the magnitude of force that I must apply to reach $\mathrm{x}$ speed? Force becomes the pillar that supports the other capacities that are decisive during competition, therefore, biomechanics through the analysis of the average propulsive speed allows manipulating the power generated by the athlete through strength training, for later transfer it to the technique and evaluate the acceleration surfaces and compare them with mathematical models, In this way, to know 
the effect caused by the application of the increase in the levels of force generated by training at speed and acceleration; With the new values, gradually modify the triangle of biomotor capacities until reaching the ideal results that allow the athlete to reach the ideal mark.

In conclusion, biomechanics quantifies the behavior of the variables force, speed, acceleration and rhythm, which allows the coach to plan based on the levels obtained in previous competition to replicate or increase the probability of reaching the first place, as well as allowing the coach to know what they are. the theoretical constants that must be achieved in an objective way. For example, to get a 10-second mark in a competition, the average propulsive speed must be X value. Finally, it is necessary to see this postulate as a future current in research to improve the performance of runners that will require time, technology, statistical studies, and mathematical forecasts that are theoretically possible. On the other hand, the psychological and physiological aspect are other components of sports performance that are trained according to the capabilities of each subject, however training with mathematical criteria and simulated projection provides quantitative information on the point at which athletes must reach based on of the triangle of motor skills postulated by Boompa.
ISSN: 2574-1241

DOI: $10.26717 /$ BJSTR.2020.31.005035

Erick Garcia Lasluisa. Biomed J Sci \& Tech Res

(c) (i) This work is licensed under Creative

Submission Link: https://biomedres.us/submit-manuscript.php

$\begin{array}{ll}\text { BIOMEDICAL } & \text { Assets of Publishing with us } \\ \text { RESEARCHES } & \text { - Global archiving of articles } \\ \text { - Immediate, unrestricted online access }\end{array}$

